\section{AUSTRALIAN CHILDREN'S PERFORMANCE AT ONE YEAR OF AGE USING THE BAYLEY SCALES OF INFANT AND TODDLER DEVELOPMENT (VERSION III)}

\author{
K. Walker ${ }^{1,2}$, R. Halliday ${ }^{1}$, S. Laing ${ }^{1,3}$, \\ N. Badawi ${ }^{1,2,4,5}$
}

${ }^{1}$ Grace Centre for Newborn Care, The Children's Hospital at Westmead, '2The University of Sydney, ${ }^{3}$ Macquarie University, ${ }^{4}$ Macquarie Foundation Professor of Cerebral Palsy, Cerebral Palsy Institute, ${ }^{5}$ Notre Dame University, Sydney, NSW, Australia

Background: Neurodevelopmental outcomes and their assessments are an essential part of Paediatric care. Standardized norm-referenced tests are widely used in neurodevelopmental assessments of infants and children as they allow comparison of neurodevelopmental status without using control groups - a practice which is often prohibitive because of cost and time constraints. As a result, most young children who are being assessed are compared to standardized norms from overseas, in particular, the Bayley Scales of Infant and Toddler Development (Version-III) (Bayley-III) which was published as a revised and updated version in 2006 and is being widely used in newborn follow-up clinics in Australia.

Aim: To compare the performance of a cohort of healthy Australian infants with the normative means of the revised Bayley Scales (Bayley-III).

Methods Healthy singleton newborns were randomly enrolled between August 1st 2006 and July 31st 2008 from the maternity units co-located to the children's hospitals in New South Wales, Australia. A total of 211 infants were assessed at one year of age using the new Bayley-III.

Results: The mean scores were significantly different from the standardized norms in all subscales except fine motor. Australian infants scored higher on cognitive and receptive language $(p<.01)$ and lower on expressive language and gross motor ( $p s$ $<.01$ ) subscales.

Conclusions: These findings raise questions regarding the validity of this test in the Australian population and suggest that the test be re-normed on Australian children for valid interpretation of scores in this cultural context. These findings may be true for other populations.

\section{CLASSIFICATION TREE APPLIED TO NEONATAL MORTALITY}

\author{
V.S. Ribeiro ${ }^{1}$, A.M. Santos ${ }^{2}$, L.A. Queiroz ${ }^{3}$
}

${ }^{1}$ Medicine III - Post Graduation in Collective Health, ${ }^{2}$ Public Health - Post Graduation in Collective Health, ${ }^{3}$ Post Graduation in Collective Health, University of Maranhao, São Luís, Brazil

Objective: The aim of this study was to establish a statistical model for prediction neonatal deaths.

Methods: A case-control study was carried out in the State of Maranhao, Northeast Brazil. The database used in this study included 446 neonates (146 cases and 297 controls). The CART method (Classification and Regression Tree) was used to construct the Tree Classification. Several trees were developed containing explanatory variables related to maternal condition and newborn infant. The tree that presented the smaller cross-validated classification error was selected. It was calculated the sensitivity, specificity and accuracy. The predictive ability of the tree to differentiate survivors and non-survivors was determined by the ROC curve. The classification tree was developed in the program R-2.7.0-WIN.

Results: The tree presented an accuracy of $88.2 \%$, sensitivity $80.7 \%$, and specificity $91.7 \%$. Moreover, it was identified four risk groups. Neonates with problems and birth weight $<2500 \mathrm{~g}$ with probability of death was $91 \%$. Second group, neonates with problems at birth and Apgar score < 7, with a probability of $70 \%$. The third group focuses neonates with congenital anomaly with probability of death of $57 \%$. Finally, in the fourth group are those whose gestational age was $<37$ weeks and probability of $53 \%$. The area under the ROC curve was 0.915 $[95 \% \mathrm{Cl}=0.87 ; 0.95]$.

Conclusion: The classification tree demonstrated good discriminatory power. It was proved to be a useful tool to determine which neonates will need more care and it can be used in the medical routine. 